\title{
EFFECT OF ADDING HIGH MOLECULAR NANOCHITOSAN ON TRANSVERSE STRENGTH OF HEAT POLYMERISED POLYMETHYLMETHACRYLATE DENTURE BASE RESIN
}

\author{
Ika Devi Adiana1, Trimurni Abidin², Harry Agusnar³, Dennis ${ }^{4}$ \\ ${ }^{1}$ Lecturer, Department of Dental Material, Universitas Sumatera Utara, Indonesia. \\ ${ }^{2}$ Professor, Department of Conservative Dentistry, Universitas Sumatera Utara, Indonesia. \\ ${ }^{3}$ Professor, Department of Chemistry, Universitas Sumatera Utara, Indonesia. \\ ${ }^{4}$ Lecturer, Department of Conservative Dentistry, Universitas Sumatera Utara, Indonesia.
}

ABSTRACT
BACKGROUND
Adding a binder to improve the mechanical properties of heat polymerised polymethylmethacrylate such as its transverse strength
is now being developed. One of them is by adding high molecular nanochitosan. This study aims to determine the effect of adding
high molecular nanochitosan on transverse strength of heat polymerised polymethylmethacrylate denture base resin.

\section{MATERIALS AND METHODS}

30 pieces (sample) of acrylic plate with size $64 \mathrm{~mm} \times 10 \mathrm{~mm} \times 2.5 \mathrm{~mm}$ were divided into 6 groups, i.e. control group and the groups with adding $0.25,0.50,0.75,1.0$ and $1.50 \% .2 \mathrm{~mL}$ nanogel chitosan was added into the mixture of acrylic resin with a P:L ratio $(23$ g: $10 \mathrm{~mL}$ ). The batter is inserted into a mould and then pressed and cured at a temperature $74^{\circ} \mathrm{C}$ for 120 minutes and then $100^{\circ} \mathrm{C}$ for 60 minutes. Acrylic plates issued for finishing. Transverse strength of acrylic resin measured using Torsee's electronic System Universal Testing Machine and analysed by one-way ANOVA.

\section{RESULTS}

The result showed a significant difference in transverse strength after the addition of nanogel chitosan with different percentages. The addition of nanogel chitosan 1.0\% produced the best transverse strength which is $79.003 \mathrm{MPa}$.

\section{CONCLUSION}

The addition of nanogel chitosan can be used to increase the transverse strength of heat polymerised polymethylmethacrylate denture base resin.

\section{KEYWORDS}

Denture Base, High Molecular Nanochitosan, Transverse Strength.

HOW TO CITE THIS ARTICLE: Adiana ID, Abidin T, Agusnar H, et al. Effect of adding high molecular nanochitosan on transverse strength of heat polymerised polymethylmethacrylate denture base resin. J. Evolution Med. Dent. Sci. 2017;6(70):4996-4999, DOI: $10.14260 /$ Jemds/2017/1085

\section{BACKGROUND}

Heat polymerised polymethylmethacrylate is commonly chosen as a material of denture base for its several advantages, i.e. simple manipulation, good dimensional stability, excellent biological and fine aesthetic properties as it resembles gingiva's natural colour. ${ }^{1}$ In spite of its advantages, heat polymerised polymethylmethacrylate has several limitations, one of it is the poor mechanical property that causes denture base to break easily. ${ }^{2}$ One of the mechanical properties of heat polymerised polymethylmethacrylate is transverse strength. ${ }^{1}$ The presence of transverse strength will cause tension in denture base during the process of chewing, eventually resulting in crack. ${ }^{3}$ Prevalence of fracture in resin denture base is $16.1 \%$ under 1 year of usage and $53.6 \%$ between $1-3$ years of usage, $16.1 \%$ were caused by the process of chewing. 4

Financial or Other, Competing Interest: None.

Submission 03-07-2017, Peer Review 20-08-2017,

Acceptance 26-08-2017, Published 31-08-2017.

Corresponding Author:

Dennis,

Jalan Alumni, No. 2 Kampus,

USU Medan 20155 ,

Sumatera Utara-Indonesia.

E-mail: devi_ika27@rocketmail.com

DOI: $10.14260 /$ jemds/2017/1085

\section{(c) (1) $(9)$}

To improve the limitation of heat polymerised polymethylmethacrylate, addition of reinforcing material is required. One of the methods is addition of natural binder, chitosan. ${ }^{5}$ Chitosan is a natural biomaterial that is continuously being developed recently as it has been proven to be medically beneficial and safe for human use. Chitosan possesses several beneficial properties such as fine biocompatibility, biodegradable, mucoadhesion, non-toxic, non-allergenic, and non-carcinogenic that lead to frequent biomedical application. According to Petri et al (2007), Glass Ionomer Cement modified with low molecular chitosan improved mechanical properties such as flexural strength. ${ }^{6}$

This study aims to determine the effect of high molecular chitosan addition in various concentrations on transverse strength of heat polymerised polymethylmethacrylate denture base material.

\section{MATERIAL AND METHODS}

Chitosan gel is made by homogenously dissolving $0.25 \mathrm{~g}, 0.50$ $\mathrm{g}, 0.75 \mathrm{~g}, 1.0 \mathrm{~g}$ and $1.50 \mathrm{~g}$ of high molecular nanochitosan powder respectively in Becker glasses filled with magnetic stirrer and $100 \mathrm{~mL}$ of $1 \%$ acetic acid on $200 \mathrm{rpm}$ hot plate for 30 minutes. The solution is added with 20 drops of potassium tripolyphosphate (TPP) and stirred for 1 hour to form gel. It was then placed in ultrasonic bath (Figure 1) for 20 minutes to break chitosan particles and centrifuged for 30 minutes at 
$3600 \mathrm{rpm}$ to form $240 \mathrm{~nm}$ nanochitosan gel measured by PSA (Particle Size Analysis). The gel residual will be added into heat polymerised polymethylmethacrylate.

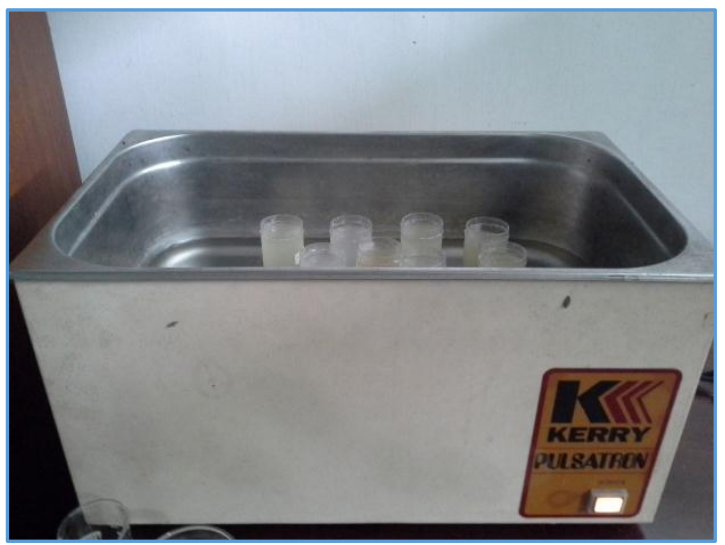

Figure 1. Chitosan Solution in Ultrasonic Bath

The samples of the study are metal plates with size of 64 $\mathrm{mm} \times 10 \mathrm{~mm} \times 2.5 \mathrm{~mm}$ (ADA Specification No. 12). Total samples are 30 pieces of metal plates, divided into 6 groups, i.e. control group (without high molecular nanochitosan addition) and groups with $0.25 \%, 0.50 \%, 0.75 \%, 1.0 \%$ and $1.50 \%$ high molecular nanogel chitosan addition. In this study, calculation of sample size was done using Federer method $((t-1)(r-1)>15)$. All samples were distributed into five groups with each group consisting of four samples.

Heat polymerised polymethylmethacrylate resin mould was constructed by mixing hard cast in water (300 g cast in $90 \mathrm{~mL}$ water) to fill bottom half of cuvette. Metal plates (size $64 \mathrm{~mm} \times 10 \mathrm{~mm} \times 2.5 \mathrm{~mm}$ ) were placed in the cuvette, their surface was parallel to that of the cast and left to set (Figure 2). After setting of cast, the surface was covered with Vaseline. The top and bottom halves of the cuvette were assembled and hard cast (300 g cast in $90 \mathrm{~mL}$ water) was poured into it. The cuvette was then placed on a vibrator. After 45 minutes, the cuvette was disassembled, the plates were retrieved and the surface was applied with cold mould seal.

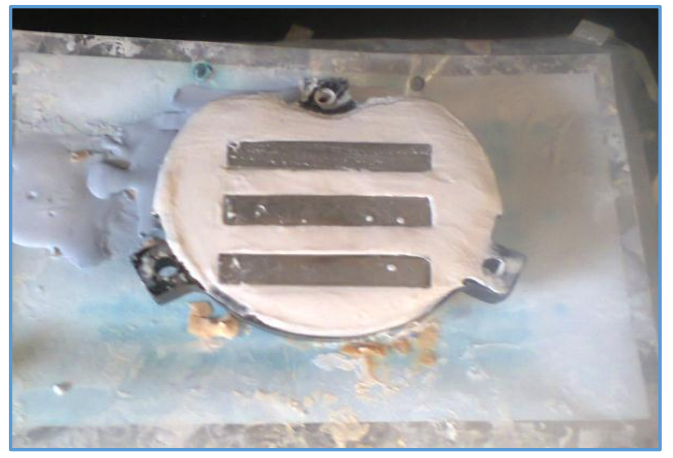

Figure 2. Placement of Plates on Cast
To fill the mould with heat polymerised polymethylmethacrylate, polymer was mixed with monomer in acrylic pot (23 gr: $10 \mathrm{~mL}$ ) and $2 \mathrm{~mL}$ of nanochitosan gel $0.25 \%, 0.50 \%, 0.75 \%, 1.0 \%$ and $1.5 \%$ respectively were added with scaling pipe (control group received no addition of nanochitosan gel), the mixture was stirred with LeCron to reach its dough-stage. The dough was then poured into the mould. The heat polymerised polymethylmethacrylate was covered with cellophane sheet and the top half of cuvette was assembled. The cuvette was then pressed with 1000 psi hydraulic press, then dissembled to rid excess acrylic resin, then re-pressed with 1200 psi press. Afterwards, the cuvette was cured. First, the cuvette was put in a $74^{\circ} \mathrm{C}$ water bath for 120 minutes. Then, the temperature was raised to $100^{\circ} \mathrm{C}$ for 60 minutes. The samples were taken out from the water bath and left for 30 minutes to cool. The samples were trimmed and polished to the desired size.

Measurement of transverse strength was performed by Torsee's Electronic System Universal Testing Machine (Figure 3). Measurement unit for this piece of equipment is MPa.

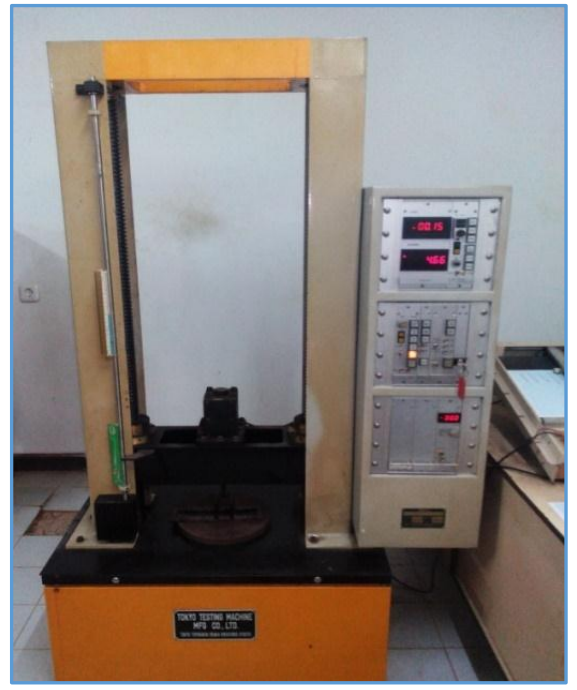

Figure 3. Transverse Strength Tester

\section{RESULTS}

The study obtained data of transverse strength change in each treatment group. Mean and deviation standard of transverse strength in all samples of heat polymerised polymethylmethacrylate denture base material without and with addition of high molecular nanochitosan gel $0.25 \%$, $0.50 \%, 0.75 \%, 1.0 \%$ and $1.5 \%$ can be observed in Table 1 .

\begin{tabular}{|c|c|c|c|c|c|c|}
\hline \multirow{2}{*}{ Sample } & \multicolumn{6}{|c|}{ Transverse Strength (MPa) } \\
\hline & Control & $\begin{array}{c}\text { Chitosan } \\
0.25 \%\end{array}$ & Chitosan $0.50 \%$ & Chitosan $0.75 \%$ & Chitosan $1.0 \%$ & Chitosan 1.5\% \\
\hline 1 & 75.734 & 79.732 & 79.850 & 78.5568 & 79.262 & 80.556 \\
\hline 2 & 72.324 & 74.676 & 73.029 & 75.3816 & 82.084 & 76.675 \\
\hline 3 & 74.911 & 68.325 & 77.498 & 80.556 & 73.500 & 78.556 \\
\hline 4 & 73.852 & 73.500 & 73.500 & 79.8504 & 79.850 & 78.204 \\
\hline 5 & 76.322 & 78.439 & 71.853 & 80.0856 & 80.320 & 78.909 \\
\hline $\begin{array}{l}\text { Mean+ } \\
\text { SD }\end{array}$ & $74.628+1.323181$ & $74.934+4.503021$ & $75.146+3.379849$ & $78.886+2.094469$ & $79.003+3.252017$ & $78.580+1.394936$ \\
\hline
\end{tabular}


Graph of transverse strength value of heat polymerised polymethylmethacrylate without and with addition of nanochitosan gel $0.25 \%, 0.50 \%, 0.75 \%, 1.0 \%$ and $1.5 \%$ can be observed in Figure 4.

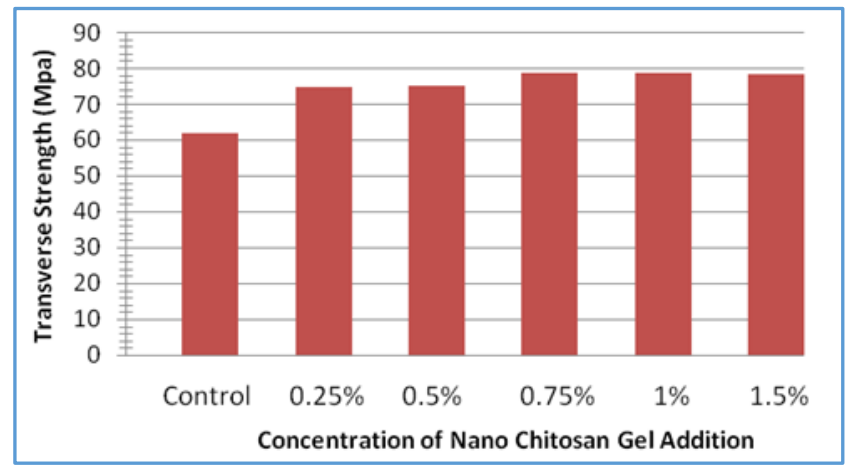

Figure 4. Graph of Transverse Strength Value of Heat Polymerised Polymethylmethacrylate without and with addition of Nanochitosan Gel 0.25\%, 0.50\%, 0.75\%, 1.0\% and $1.5 \%$.

Figure 4 shows increase of transverse strength in each treatment group. Addition of $1 \%$ nanochitosan gel gives significant transverse strength compared to other treatment groups.

Normality test in the study resulted in normal distribution of data ( $p>0.05)$. In the study, effect of $0.25 \%$, $0.50 \%, 0.75 \%, 1.0 \%, 1.5 \%$ nanochitosan gel addition on transverse strength on heat polymerised polymethylmethacrylate is analysed by one-way ANOVA, (significance value, $\mathrm{p}<0.05$ ). This shows that addition of nanochitosan gel $0.25 \%, 0.50 \%, 0.75 \%, 1.0 \%$ and $1.5 \%$ improves transverse strength of heat polymerised polymethylmethacrylate. To make sure the difference of transversal strength, Least Significance Difference (LSD) test can be observed in Table 2 .

\begin{tabular}{|c|c|c|c|}
\hline (I) Group & (J) Group & Mean Difference (I-J) & Sig. \\
\hline \multirow[t]{5}{*}{ Control } & $0.25 \%$ & $-12.743920^{*}$ & 0.000 \\
\hline & $0.5 \%$ & $-12.955600^{*}$ & 0.000 \\
\hline & $0.75 \%$ & $-16.695280^{*}$ & 0.000 \\
\hline & $1.0 \%$ & $-16.812880^{*}$ & 0.000 \\
\hline & $1.5 \%$ & $-16.389520^{*}$ & 0.000 \\
\hline \multirow{4}{*}{$0.25 \%$} & $0.5 \%$ & -0.211680 & 0.909 \\
\hline & $0.75 \%$ & $-3.951360^{*}$ & 0.041 \\
\hline & $1.0 \%$ & $-4.068960^{*}$ & 0.036 \\
\hline & $1.5 \%$ & -3.645600 & 0.058 \\
\hline \multirow[t]{3}{*}{$0.5 \%$} & $0.75 \%$ & -3.739680 & 0.052 \\
\hline & $1.0 \%$ & $-3.857280^{*}$ & 0.046 \\
\hline & $1.5 \%$ & -3.433920 & 0.073 \\
\hline \multirow[t]{2}{*}{$0.75 \%$} & $1.0 \%$ & -0.117600 & 0.949 \\
\hline & $1.5 \%$ & 0.305760 & 0.869 \\
\hline $1 \%$ & $1.5 \%$ & 0.423360 & 0.819 \\
\hline \multicolumn{4}{|c|}{$\begin{array}{l}\text { Table 2. Least Significance Difference (LSD) of } \\
\text { Transverse Strength Test of Heat Polymerised } \\
\text { Polymethylmethacrylate Denture Base Material }\end{array}$} \\
\hline
\end{tabular}

The result of LSD in Table 2 shows the significant difference between control group and addition of nanochitosan gel $0.25 \%, 0.50 \%, 0.75 \%, 1.0 \%$ and $1.5 \%$ with $\mathrm{p}$ value $=0.000(\mathrm{p}<0.05)$.

\section{DISCUSSION}

Results in Table 1 shows mean differences in transverse strength of heat polymerised polymethylmethacrylate without and with addition of high molecular nanochitosan gel $0.25 \%, 0.50 \%, 0.75 \%, 1.0 \%$, and $1.5 \%$. Increase in transverse strength was observed after addition of high molecular nanochitosan gel. While increase of transverse strength was observed after addition of $1.5 \%$ nanochitosan gel, the value of transverse strength was lower than that of group with $1 \%$ nanochitosan gel addition. This is due to high viscosity and different density of chitosan solution. Mixing heat polymerised polymethylmethacrylate denture base material with high viscous $1.5 \%$ nanochitosan gel resulted in difficulty of diffusion to fill pores in polymethylmethacrylate to bind and improve mechanical strength. This will decrease density of heat polymerised polymethylmethacrylate denture base material, eventually decreasing its transverse strength compared to group that was added with $1 \%$ nanochitosan gel.

The study shows addition of $1.0 \%$ nanochitosan gel as optimal concentration to improve transverse strength of heat polymerised polymethylmethacrylate. The transverse strength could be observed highest in group with addition of $1.0 \%$ nanochitosan gel, measuring $79.000 \mathrm{MPa}$, and lowest in control group, measuring 74.628 MPa.

Trong-Ming (2001) conducted research on structural change and thermal properties of PMMA with addition of 1$15 \mathrm{~g}$ and showed that the best structure of chitosan-modified PMMA is found in group with $1 \mathrm{~g}$ addition. This study shows addition of $1.0 \%$ nanochitosan gel to heat polymerised polymethylmethacrylate denture base material as the optimal concentration. ${ }^{7}$

The study shows that addition of nanochitosan gel to heat polymerised polymethylmethacrylate denture base material increased the transverse strength. The result is consistent to the study of Florez-Ramirez et al (2008) that stated addition of chitosan to PMMA increased hardness and modulus of elasticity.

Amer et al (2014) stated that tensile strength and young modulus properties of PMMA increased along with the percentage of chitosan. The increase is due to increasing physical and chemical interaction between massive molecule and effective chain such as $\left(\mathrm{NH}_{2}-\mathrm{OH}-\mathrm{COO}, \mathrm{C}=0\right)$. These bonds are formed between polymer chain during polymerisation, where $-\mathrm{CH}_{3}$ in heat polymerised polymethylmethacrylate will bind with $-\mathrm{OH}$ in the polymer chain of chitosan. ${ }^{8}$ More cross bonds formed in the polymer chain will cause more formation of continuous three-dimensional structure, resulting in stiffer and tougher structure that could endure certain force or pressure. ${ }^{9}$

\section{CONCLUSION}

Based on the above results, it is concluded that the addition of $0.25 \%, 0.50 \%, 0.75 \%, 1.0 \%$ and $1.5 \%$ of nanochitosan gel increases transverse strength of heat polymerised polymethylmethacrylate. Addition of $1 \%$ nanochitosan gel is the optimal concentration of reinforcing material to increase transverse strength of heat polymerised polymethylmethacrylate denture base material. 


\section{REFERENCES}

[1] Anusavice KJ, Phillips RW, Shen C, et al. Phillips' Science of dental materials. $12^{\text {th }}$ edn. USA: St. Louis Mo, Elsevier Saunders 2013: pgs. 89, 91, 261, 722, 724, 727-8, 735, 737, 739, 741-4.

[2] Raszewski Z, Nowakowska D. Mechanical properties of hot curing acrylic resin after reinforced with different kinds of fibers. Int J Biomedical Materials Research 2013;1(1):9-13.

[3] Bashi KT, AL-Nema LM. Evaluation of some mechanical properties of reinforced acrylic resin denture base material (an in vitro study). Al-Rafidain dent J 2009;9(1):57-65.

[4] El-Sheikh AM, Al-Zahrani SB. Causes of denture fracture: a survey. Saudi Dent J 2006;18(3):149-53.

[5] Flores-Ramirez N, Luna-Bárcenas G, Vásquez-García $\mathrm{SR}$, et al. Hybrid natural-synthetic chitosan resin: thermal and mechanical behavior. J Biomater Sci Polymer ED 2008;19(2):259-73.
[6] Petri DF, Donega J, Benassi AM, et al. Preliminary study on chitosan modified glass ionomer restoratives. J Dent Materials 2007;23(8):1004-10.

[7] Trong-Ming D, Shih-Chang H, Wen-Yen C. Structures and thermal properties of chitosan-modified poly(methyl methacrylate). J of Polymer Science 2001;39:1646-9.

[8] Amer ZJA, Ahmed JK, Abbas SF. Chitosan/PMMA bioblend for drug release applications. Int J Eng and Tech 2014;4(5):318-24.

[9] Sugita P, Wukisari T, Sjahriza A, et al. Kitosan sumber biomaterial masa depan. Bogor: IPB Press 2009: pgs. $27,82-108,125$. 